\title{
Causes of School-Based Violence in South African Public Schools: Application of Normalisation Theory to Understand the Phenomenon through Educators' Perspectives
}

T Netshitangani

University of South Africa

Email: Netsht1@unisa.ac.za

\author{
Doi:10.5901/mjss.2014.v5n20p1394
}

Abstract

The article uses the normalisation theory to understand, through the analysis of educators' perspectives, how school-based violence could be curbed in South African public schools. School-based violence is mostly the result of the normalisation process whereby children who are exposed to more risk than protective factors are said to be more likely to use violence. The causes of school-based violence, as revealed in the small-scale study conducted in South Africa, are discussed. The main aim of the study was to examine educators' perspectives on violence in schools. The objective of the study was to look at causes of school violence and how the school managers and educators are coping with violence. Qualitative research was used and individual and focus group interviews were conducted to collect data from school management teams and educators. The findings indicate that while children who are not exposed to violence can still be violent, children who are constantly exposed to violence display violent behaviours more often than those who are not. The article then suggests the incorporation of the Invitational Educational theory of practice as a strategy to reduce school-based violence as this theory takes into account the normalisation of violence among children..

Keywords: peer influence, mass media; invitational theories, violence reduction strategies, school management teams

\section{Introduction and Background}

Violence and crime are prevalent antisocial maladies in a significant number of schools in South Africa. These maladies have, ostensibly, had debilitating effects on learning and teaching. This reality, that crime appears to be a way of life in South Africa, has also been expressed by Le Roux \& Mokhele (2011: 318). Shootings, stabbings, and physical and emotional violence have taken place in both public and private schools (Akiba, LeTendre, Baker \& Goesling 2002; Zulu, Urbani \& Van der Merwe 2004). Trends are emerging that suggest that the requisite environment for effective learning and teaching is increasingly being undermined by a growing culture of school violence and that this is impacting negatively on the education sector (United Nations Children's Fund, 2001:1). In addition, violence and crime directly affect teaching and learning - as well as school principals' and educators' managerial and instructional duties - with the consequence that the problem of low-quality education outputs is exacerbated. The extent to which the media focused on such incidents confirms their seriousness. It is therefore important to critically analyse the causes of violence in order for the School Management Teams (SMTs) to be able to align the strategies to be employed in eliminating the scourge of violence in schools

Schools have inadvertently become territories prone to crime and violence and this represents a threat to the successful achievement of educational goals. The problem persists despite the South African Police Services (SAPS) and the Department of Education (DoE) having a number of Safer Schools initiatives in operation - including the piloting of Firearm-Free Zones for Schools in accordance with the Firearms Control Act 60 of 2000 and the search and seizure of dangerous weapons and drugs in terms of the Education Laws Amendment Act 31 of 2007. While the country's Safer Schools Campaign has made major gains, it is increasingly clear that much more still needs to be done.

School violence is a many-faceted problem, making it difficult for researchers and practitioners to pinpoint and explain its causes. The South African Human Rights Commission Report on School-based Violence (2008) also enumerates the factors contributing to school-based violence. Among these factors are the different social settings within which young people operate -, including the school environment, the family and the broader communities in which they live. The different settings in which schoolchildren find themselves, as well as the people that they come into contact with in these contexts, "converge to constitute a significant source of risk for violence" (Burton and Leoschut, 2012: 54)

Little research has been conducted on the understanding of causes of violence using normalisation theories. Most studies in South Africa and worldwide (Du Plessis, 2008, South African Council of Educators' (SACE) report, 2011; 
Burton, 2008a; Brown and Winterton 2010; Burton and Leoschut 2012; Shier, 2008) have investigated the violence phenomenon in general, with causes of violence being just a small section of the studies. However, it is clear, where causes are mentioned, that these mainly span a range of defined problems, namely poverty, unemployment, patriarchal notions of masculinity, vulnerabilities of families and exposure to violence in childhood, widespread access to firearms, alcohol and drug misuse, peer group influences, permanent exclusions of learners from schools because of bad behaviour, a weak culture of enforcement, and failure to uphold safety as a basic right.

Studies conducted in South Africa and internationally, (which include Du Plessis, 2008; SACE report, 2011; Burton, 2008a; Brown and Winterton 2010; Burton and Leoschut 2012; Shier, 2008) give recommendations on how to eliminate violence, though these consist mainly of traditional law enforcement strategies. The issue at hand, however, is that school violence persists nonetheless. This article attempts to explain the causes of school-based violence using normalisation theory. These causes were revealed by the findings of the study conducted in South African schools. The broader intentions and purposes of this study on school-based violence were to examine educators' perspectives on violence in schools, its causes, and how they address it. In that regard, the following sub-questions were regarded as being critical to the aims of the study: What is the nature of violence in schools? What are the causes for escalating school-based violence? This article - in support of their endeavour to reduce violence - uses normalisation theory to analyse the causes of violence with a view to recommending the best way of eliminating violence in schools. Understanding causes of violence using the normalisation theory assists school managers greatly in the development of the strategies for curbing violence in schools. The article expounds on the various causes which - individually and jointly - lay the foundation for, as well as extend and escalate, the incidence of school-based violence in South Africa.

\subsection{Normalisation theory}

The literature review was compiled with reference to current international debate around learners who are exposed to various kinds of crime and violence at schools, including physical and sexual assaults, robberies, intimidation, bullying, shootings, stabbings, gangsterism and drug trafficking (Burton and Leoschut, 2012; SACE report on School-Based Violence Report, 2011; Brown, and Winterton, 2010; Burton, 2008a; Du Plessis, 2008; Burton , 2008b; Neill, 2008; Shier, 2008; De Wet, 2007; White S, 2007).

In order to understand the educators' perspectives, the line of argument of this article follows normalisation theory. This theoretical framework was influenced by the work of Ward (2007, in Burton, 2007) who argues that children who are exposed to more risk factors than protective factors are more likely to use violence. Thus, normalisation of violence is a result of the high rate at which crime takes place. Burton (2007, cited in Business Day, Tuesday, May 20 2008, p. 4), of the Centre for Justice and Crime Prevention (CJCP), points out that "...because young people's sense of identity is shaped by what they see around them, and because crime is so rife, many of SA's school children see crime and violence as normal". According to Ward (2007, in Burton 2007), this normalisation of the behaviour of children takes place within five ecological contexts: the individual level, the microsystems level, the mesosystems level, the exosystem level, and the macrosystem level. A brief description of each level is stated below.

The individual level: Individual attributes such as gender, age, impulsivity, inattention and hyperactivity, substance abuse, the inability to feel guilt, and one's own victimisation are risk factors that are likely to increase aggressive behaviour (Ward, 2007, in Burton, 2007).

The microsystems level: This level is about the everyday social contexts in which children develop and how these influence the way in which they react to situations. These contexts are: the family, the school, the peer group, and afterschool and leisure activities (Brown and Winterton, 2010, Shier, 2008, White, 2008). Thus, children who are exposed to conflict and family violence - including intimate partner violence and child abuse - are exposed to models who demonstrate violent behaviour to solve problems and are likely to emulate the behaviour itself and think that it is rewarded. "Since violence in these families is normalised, rather than condemned, the standards by which children learn to judge violent behaviour are implicitly favourable towards violence" (Ward, 2007 in Burton, 2007: 19). Some schools model violence for learners by using corporal punishment, which is illegal in South Africa (Mncube and Harber, 2012; Mncube and Netshitangani, 2014; PLAN 2008; Smith and Vaux 2003). In the context of poor family monitoring and low school safety, it is likely that youth in South Africa and internationally are socialising each other into violent behaviours.

The mesosystem level: Public perceptions of school violence have also linked it to factors external to the school. Laub and Lauritsen (1998, p. 127) state that "...conventional wisdom holds that school violence is a reflection of violence in the broader social context, that is, violence is imported into a school by the students, and by intruders from the neighbourhoods surrounding the school." Factors outside of school, such as exposure to crime, violence, drugs, as well as family factors such as parental involvement in crime, violence, drugs, and whether or not the student has only one 
parent, also increase the likelihood of violent student behaviour (Smith \& Smith, 2006; Kandakai, Price, Tellojohann, \& Wilson, 1999; Kotlowitz, 1991).

The exosystem level: Factors such as the neighbourhood, the mass media, parenting, schools and the formation of peer groups constitute a major component of this level. Accordingly, socioeconomic factors affect children's survival, protection and development. The mass media is one of the effective social influences on children. According to Huesmann (1999) international research shows that, where children are exposed to violent images on television and live violence in an environment that does not have strong anti-violence norms, they are likely to become more aggressive.

The macrosystems level: Socioeconomic aspects, as well as the attitudes and ideologies of culture, are not tangible but they are influential. Children from poor families, and from neighbourhoods where the majority of families are poor, are more likely to engage in violent behaviours or criminal activities for purposes of obtaining both luxury goods and basic necessities (Shier, 2008; Smith \& Smith, 2006). Furthermore, the alternative contraband market based on stolen goods, guns, and drugs, is given space to flourish (Motsei, 1998). In addition, the culture of violence has been pervasive in South Africa since 1976 when there were protests to change the curriculum and this situation has persisted in the postapartheid era (Ward, 2007 in Burton, 2007; Scott Granberg-Rademarker, 2007). Thus, violent protests are more likely to be "normal" or acceptable to learners (Ndebele, 2007; Loots, 2005).

To curb school violence, schools have relied primarily on traditional law enforcement methods, including metal detectors, security guards, closed-circuit television, locking all doors and windows except for one or two entrances, and conducting "shake-down" searches and locker checks. While sometimes effective, traditional law enforcement methods carry major negative side effects. These include a significant financial burden, a reduction of time for classroom instruction, and a decline in both teacher and student morale. In addition they create a pervasive atmosphere of apprehension among staff, learners, and parents.

\subsection{Invitational Educational theory of practice}

In pursuit of eliminating school-based violence, a number of researchers (Juhnke \& Purkey, 1995; Novak, 2002; Purkey, 2000; Purkey \& Schmidt, 1996; Purkey \& Siegel, 2003; Shoffner \& Vacc, 1999; Stanley \& Purkey, 1994) advocated for Invitational Educational theories of practice. These researchers argue that implementing Invitational Educational theories provides a framework for making schools a more exciting, satisfying, and enriching experience for everyone, including all visitors, as it goes beyond reforming or restructuring: its goal is to transform the fundamental character of the school. Invitational Education asserts that everybody and everything in and around schools adds to, or subtracts from, school safety. It centres on four guiding principles of respect, trust, optimism, and intentionality. Moreover, the Five Ps (people, places, policies, programmes, and processes), provide the means to implement Invitational Educational theories (Purkey \& Novak, 1996).

\section{Research Design and Methods}

\subsection{Methodology}

This article is based on a pilot study of a comprehensive countrywide research that was to follow. Qualitative research methodology was used to conduct the study. Data was gathered from, principals, school management teams (SMTs) and other educators, and the parental components of school governing bodies (SGBs). Data collection for the study therefore involved desk review of relevant documents and materials, reports, evaluations, previous studies, newspapers and related policies as well as in-depth interviews with principals and focus-group discussions with SMTs, educators and SGBs. During the period at which the study was conducted, in 2009, the media had publicised the violence-related incidents taking place in schools to a great extent, and that warranted a more comprehensive study in order to understand the causes of violence in South African schools.

\subsection{Sample selection and data collection}

Four schools in Gauteng province were visited. Typical case sampling was used to select the sites for the research. Schools that had experienced some form of violence, either serious or light violence-related incidents, were selected by reviewing newspaper articles and by asking the provincial officials to recommend the schools. Interviews were used to gather data. Semi-structured interviews with open-ended questions were employed in order to allow the interviewees to use their own ways of defining their own worlds, and to raise other issues important to them that may not have been 
included in a schedule prepared by a researcher (Marshall, and Rossman, 2010; Patton, 2008: Silverman, 2010: Flick, 2009). Focus group interviews were used because they encourage participation and interaction amongst participants and this creates a dynamic context where participants, together, create meanings concerning the research questions (Krueger, 2009). Each principal was interviewed individually. Variations of three to five SMT members and educators were interviewed in focus groups in each of the four schools. One SGB member (parent component) from each school was also interviewed to triangulate the data. Thus, four different instruments were used. Each instrument used similar questions, but each of them was customised so as to fit each category of interviewees.

\subsection{Analysis of data}

Analysis was done thematically using predetermined themes from the literature. Emerging themes from the data were also analysed and interpreted. Similar responses were grouped together into categories. Similar codes were aggregated to form a major idea from the data (Cresswell, 2010). The choice and rationale for the four schools sampled in the study reflected the nature, rather than the type, of the investigation. (Strydom, 2002: 211). Since the study was part of a comprehensive countrywide initiative that was to follow, the latter "type" of study conforms to an intrinsic case study approach. According to this approach, the four schools were each viewed taking into account their unique and individual uniqueness (Fouche, 2002: 276).

\subsection{Ethical consideration}

As a study that involved research on human subjects, the collection of private or personal information, or the participation of individuals in individual interviews and focus group interviews was designed in such a way that it protected the privacy, dignity, and integrity of the respondents. This was accomplished by ensuring confidentiality and anonymity to all participants. In addition, to protect the learners who were involved in violence-related incidents, the real names of the schools were not used when reporting on the findings. Instead, the schools were referred to as school 1, school 2, school 3 , and school 4.

\section{Discussion on Findings}

According to Burton (2008), for one to gain a sense of the causes of violence in schools, one needs to examine and attempt to understand the broader context in which the school is located. "This way of understanding school-based violence will minimise the possibility of this problem being reduced to the level of the individual in which the particular parties involved in the violence are viewed as the sole problem"(SACE School-based violence report: an overview of School-based Violence in South Africa: 2011: 23). The context of the schools becomes the means by which it is established whether or not there is a correlation between both the internal and external environments, and the prevalence of forms of violence in the school. The variables in the context description of this study, racial demographics, and school location, are not necessarily peculiar to school-based violence, nor are they necessarily contributing factors.

\subsection{A synopsis of the internal environment}

\subsubsection{The school premises/grounds}

In comparing the schools themselves, the grounds of the first school to be visited (school 2) were found to be the most aesthetically appealing, followed by school 1 , school 2, and school 3 . The gardens at the first three schools were also found to be well kept. Most significantly, there was no loitering on the part of either learners or educators during teaching time at the first three schools and no noise could be heard in the corridors. At the first two schools learners were punctual. This could be clearly noted as the school visits took place during the mornings.

Conversely, at school 4 , noise could be heard on entering the school. During changeover of periods, learners made noise in the corridors and this was compounded by the frequent announcements or instructions from the school's public address system in the administration building. This however, cannot lead to characterisation of the school as chaotic. 


\subsubsection{Learner and educator racial/demographic distribution}

School 1 was predominantly white in both the educator and learner components. School 2 was predominantly populated by black learners, and a multiracial educator component. School 3 was populated by predominantly black (African and coloured) learners and a fairly multiracial educator component. This was a special school for learners categorised as "mildly mentally handicapped". (Such learners require special, professionally acquired skills on the part of the educators.) School 4 was populated by a completely black (African, coloured (bi-cultural), and Indian) learner constituency, with the majority being African. The same demographic allocation applied to the educator component.

\subsection{A synopsis of the external environment}

School 1, with its predominantly white learner population, was situated in a predominantly white/Afrikaans mixed-income community. School 2 was located in a predominantly white middle-income suburb. The predominantly black student population implies that learners were from outside of this suburb. School 3 was located in a low-income, predominantly coloured area. School 4 was in a predominantly Indian and coloured area. The majority of the African learners attending school 4 came from outside this area.

It is possible that the appropriateness of socio-economically-derived nuances such as "low- or high-income" groups, and "upper-, or middle-class" could be contested here. it is noted that these terms are used in this context in a relative sense; that is, by way of comparison with other, adjacent, residential areas.

\subsection{Causes of school violence}

This article attempts to discuss different causes or factors, as revealed by the pilot study, which alone and jointly lay the foundation for (as well as extend and escalate) the high incidence of school-based violence in South Africa. It further draws on normalisation theory in an attempt to understand school-based violence and it discusses a number of causes for such violence (listed in the following paragraph) which emerged from the data gathered.

In response to the questions, "What do you think are the causes of school based violence amongst learners?" and "What do you think are the causes of school-based violence by learners to educators?" the following causes were highlighted by participants: A lack of values among learners due to a lack of parental care; peer influence; unguided exposure to media; psychological factors; and poor socio-economic background. These causes closely mirror the causes already mentioned in the literature review section.

\subsubsection{Poor parental care}

Participants attributed incidents of violence to poor parental care. A lack of role-modelling by parents of learners was also highlighted as a challenge. Participants expressed the opinion that dysfunctional family backgrounds and structures had led to learners - especially those of high school age - taking up the role of family heads. Moreover, such learners were also seen to be extending "their "head-of-household status"' on other learners and educators. Participants further indicated that, in families headed by single mothers, boys lacked father figures they could emulate as role models. In addition, even in "normal" families, constant fights between parents were seen to create undesirable impressions on the children involved. One female teacher supported the view of poor parental care and lack of role modelling by parents citing her own experience:

Parents are trying to be friends to their kids by compromising on proper parental care. Sometime ago we phoned a learner's home to say we want to speak to the girl and the mother answered she is at school unfortunately now. When we replied that she is not here (at school) we are phoning from the school, the mother quickly said 'I forgot she is sick in bed'. You see, parents are trying to control their kids with love without any regard for the consequences of their bad behaviour.

The above utterance clearly shows that some parents can be bad role models and children tend to emulate what is practiced by their parents as behaviour by parents and role models is seen as normal. Where bad behaviour is not condemned by a parent children think, at the mesosystem level, that such behaviour can be simulated (Ward, 2007 in Burton, 2007). 
At school 2, the school management team indicated that the single parent of a "serial" and unrepentant offender was an educated nurse, suggesting that she was aware of the pivotal role she had to play in her son's development. Ironically, the school management expressed that she continued to refute the school's view of her son's involvement in violent acts, sending a message to the child that violence was not a problem. At school 1 , the parents of an aggressive learner were regarded as a normal family. However, the participants indicated that they were not actively involved in the supervision and monitoring of their son's private life. The point here is that a lack of parental involvement in the lives of learners provides a fertile environment for children to exhibit violent behaviour (Brown and Winterton, 2010; Smith \& Smith, 2006, Kandakai, Price, Tellojohann, \& Wilson, 1999). It was not surprising that the participants said that learners who seldom received attention at home looked for attention while on the school premises, but in a negative way. In addition, participants identified competition for partners as the major cause of violence among learners in schools, a matter which relates to a lack of parental guidance in our society.

Participants also expressed the view that learners who came from "normal" family backgrounds were aggressors too. (This refers to families in which both parents are present, but who live in surroundings which are violence stricken.) Interestingly, this is in agreement with the assertion in normalisation theory school violence is sometimes a reflection of violence in the broader social context (Laub and Lauritsen, 1998).

Closely related to the matter of lack of parental care raised by the interviewees was a lack of the kind of values that would require learners to listen to their elders and the general decline of morals and values in society. This lack of respect was attributed to poor parental care. The educators were so disturbed about this to the extent that one participant said:

It is not the educators' duty to train learners how to respect elders, the duty of educators is to teach. (Educator)

It was indicated that many parents were losing the battle against bad role-modelling. There are parents who are not exemplary and indirectly transmit unacceptable values to their children. Again, the issue of normalisation of behaviour is apparent in the view of these educators that children are products of their social context (Brown and Winterton, 2010, Shier, 2008, White, 2008). What these educators are not saying, however, is that some schools are also modelling unacceptable behaviour, including violent behaviour for learners, which is also imitated by learners. As mentioned in the theory section, the point here is that the literature (Mncube and Harber, 2012, Mncube and Netshitangani, 2014, Pinheiro 2006; PLAN 2008; Smith and Vaux 2003) reveals that some schools model this behaviour through the use of corporal punishment and verbal abuse - neither of which in any way teaches children respect for other people. It is then evident that normalisation at microsystems level is strong and is acknowledged by the educators. As mentioned by previous researchers (Brown and Winterton, 2010, Shier, 2008, White, 2008), people's actions and behaviour in these contexts (the family, the school, the peer group, and after school and leisure activities) influence the way in which learners react to situations.

\title{
3.3.2 Exposure to mass media
}

Closely linked to lack of proper parental care, it emerged in the study that the exposure of children to television without parental guidance was one of the major causes of violent behaviour. Participants indicated that some parents are busy from morning to late evening due to work and other responsibilities, leaving their children all alone at home to spend much of their time watching television:

\begin{abstract}
What they watch are mainly the movies which contain violent and disrespectful behaviours in the name of freedom of speech and other immoral activities leading to poor upbringing of children these days. All these contribute to aggressive and disrespect for authority and for elders such as teachers at school. (Educator)
\end{abstract}

According to Huesnam, et al, op cit (1999) cited in the introduction, research shows that, where children are exposed to violent images on television and to live violence in an environment that does not have strong anti-violence norms, they are likely to become more aggressive. Mirroring this, participants perceived the causes of violence in schools to be a societal problem. On this score, some participants argued that there was no such thing as school violence because the school forms part of the larger community and that violence there should be viewed as any other violence. This suggests that teachers and school principals feel it simply to be more convenient to talk about "violence in schools" than "school-based violence".

Related to media influence is the role of the electronic and print media, as well as the "entertainment industry". The damage done by the latter is compounded by the preponderance of morally-suspect music videos and films which learners can easily download to their cell phones. Some learners mete out violent acts and behaviour to their peers and 
educators in order to emulate or "act out" something observed at home or via "the entertainment media". Such practices are so frequent that children perceive them as normal and other parents, moreover, don't think there is anything wrong with such occurrences and are not aware of how influential the mass media can be.

\subsubsection{Poor socio-economic background of learners}

In response to the question, "What is the social background of the learners who were perpetrators of violence in the school?" the responses given, in general, were poor family backgrounds, illiterate parents and child-headed families. In the words of one respondent:

\section{Learners come to school with a "violent baggage" from home and society alike. (Principal)}

In agreement with what these educators expressed, Smith \& Smith (2006) and Haynes (1996) argue that such factors increase the likelihood of violent student behaviour. Another critical cause of violence identified from the respondents' answers was the poor socioeconomic backgrounds of learners. Participants echoed what is argued in the literature, that learners from poor or disadvantaged backgrounds appear to be more aggressive. They attributed this to a lack of proper parental care due to poverty and a lack of control due to low levels of education. As previously noted, normalisation theory emphasises that poverty causes children to engage in violent behaviours or criminal activities in order to obtain both luxury goods and basic necessities they do not have (Shier, 2008; Smith \& Smith, 2006). Of concern is that socioeconomic aspects and the attitudes and ideologies of such culture are not tangible, although they are highly influential. One educator had this to say:

Learners from poor parents have their needs such as food and clothing unmet which thereby make them more aggressive and unfriendly.(Educator)

In addition, the respondents expressed that society should set exemplary norms and values. For instance, they were of the opinion that corruption by politicians who were found to be embezzling government money, which was in the news during the period in which the study was conducted, may have instilled in the minds of many learners the view that "corruption" and therefore, "aberrant behaviour" both pay. As such, the participants said that unacceptable private and public behaviour should not be seen to be rewarded.

\subsubsection{Peer influence}

Peer pressure was seen as a serious contributor towards the problem of violence. Because the majority of perpetrators outside the school are seen as successful "heroes" on account of their criminal exploits, they are emulated by their peers in the school. Literature (Brown and Winterton, 2010; Shier, 2008; White, 2008) has mentioned peer influence as one of the common causes of violence. Affected children - because they see other children committing crime -tend to think that violence is good. Critical here is that the learners' sense of identity is shaped by what they see around them (Ward, 2007). There seems to be no doubt that incidents of violence take place in schools in reaction to crime happening around them.

\section{Conclusion}

This study reveals there are many causes for in-school violence. The most influential of these is the extent to which the child sees violence as normal because of the extent of the violent acts he or she is exposed to. The findings of this study confirm that, generally, children who are exposed to more risk factors than protective factors are more likely to use violence. They can thus indeed be said to have been normalised to being violent. Poor parental care leads to a lack of respect on the part of children and a decline in their values. Additionally, unguided exposure to mass media allows children to copy and imitate violent acts while poor socioeconomic backgrounds lead children to engage in criminal activities in order to acquire basic necessities. Thus, because children are normalised to being violent, school-based reduction measures must look beyond traditional law enforcement methods and incorporate Invitational Educational theories of practice. This theory is more inclusive in reducing violence providing a framework for making schools a more exciting, satisfying, and enriching experience for everyone - including students, staff, parents and visitors. As mentioned in the introduction, the goal of the Invitational Education theory of practice is to transform the fundamental character of 
schools (and thus of everybody and everything in and around such schools) through its emphasis on the four guiding principles of respect, trust, optimism, and intentionality. Therefore the parents and other members of the community outside the schools can be reached and educated through the involvement of school governing bodies, learner representatives and the rest of the learner community.

Surprisingly, participants' recommendations on the prevention and management of violence in schools were in line with the employment of Invitational Educational theory of practice in general. They expressed the opinion that prevention of the problem is better than management of the problem after the fact. When asked, "What do you think must be done to eliminate school-based violence?" their responses included that:

- educators should be empowered and capacitated to effectively deal with violence and indiscipline in general and that, moreover, the Department of Basic Education should provide support to teachers - particularly young teachers - by developing rules and policies that are strict and urgent in their application

- moral values should be promoted and that this should begin at home and in society as learners tended to learn bad manners in society and then bring these onto school premises - participants thus recommended that parents must instil discipline in their children through proper and adequate parental guidance

o teamwork among teachers and parents along with the involvement of the public and all stakeholders would improve the situation.

o the media should not sensationalise stories on school-based violence, but should rather be sensitive to the feelings of all the affected parties lest the emotional intelligence of learners may affected - the aim of media reporting on incidents of violence should be to educate the public, rather than to exaggerate and distort facts.

The recommendations thus made by the participants are in line with Invitational Education theory of practice. The integration of Invitational Education theory of practice is therefore recommended when schools develop measures to curb school-based violence.

Beyond the obvious and pressing need to create and maintain safe schools, there is also the primary responsibility for learners' academic achievement. It is possible to create a school where everyone is safe, but such a school would resemble a fortress more than a school. Invitational Educational theories present a way of creating and maintaining schools that are both safe and conducive to academic success.

\section{References}

Akiba, M., LeTendre, G. K., Baker, D. P., \& Goesling, B. (2002), Student victimization: National and school system effects on school violence in 37 nations. American Educational Research Journal, 39: 4, 829-853

Brown, J. \& Winterton, M. (2010), Violence in UK schools: what is really happening? British Educational Research Association (BERA), 36-37.

Burton, P. (2007), cited in Business Day, Tuesday, May 20 2008, 4.

Burton, P. (ed.) (2007), Someone stole my smile: An exploration into the causes of youth violence in South Africa. Cape Town: CJCP Monograph Series, 3.

Burton, P. (2008a), Snapshot results of the CJCP National schools violence study. Centre for Justice and Crime Prevention Research Bulletin, 2.

Burton, P. (2008b). Dealing with School Violence. Cape Town: CJCP Issue Paper No 4.

Burton, P. \& Leoschut, L. (CJCP) 2012, School Violence in South Africa. Results of the 2012 National School Violence Study.

Creswell, J. W. (2013), Research design: Qualitative, quantitative, and mixed methods approaches. London: Sage Publications, Incorporated.

De Wet, N.C. (2007), Free State educators' perceptions and observations of learner-on-learner and educator-on-learner school violence. Education as Change 11: 1, 59-85.

Du Plessis, A. H. Exploring secondary school educator experiences of school violence (Master's Thesis).

Flick, U. (2009), An introduction to qualitative research. London: Sage.

Fouché, C. B. (2002). Research strategies. Research at grassroots for social sciences and human service professions. Pretoria: Van Schaik.

Harber, C. ( 2004), Schooling as violence: How schools harm pupils and societies. New York: Taylor and Francis Group.

Huesmann, L. R. (1999), The effects of childhood aggression and exposure to media violence on adult behaviours, attitudes, and mood: Evidence from a 15-year cross-national longitudinal study. Aggressive Behavior, 25, 18-29.

Juhnke, G. A. \& Purkey, W. W. (1995, February), An invitational approach to preventing violence in schools. Counseling Today, pp. 50, $52,55$.

Kandakai, T.L., Price, J.H., Tellojohann, S.K. \& Wilson, C.A. (1999), Mothers' perceptions of factors influencing violence in schools. The Journal of School Health, 69: 5, 189-195.

Krueger, R. A. (2009), Focus groups: A practical guide for applied research. London: Sage.

Laub, J.H. \& Lauritsen, J.L. (1998), The interdependence of school violence with neighborhood and family conditions. In Violence in 
American schools: A new perspective. In Elliot, D.S., Hamburg,

B.A. \& Williams, K.R. (Eds.). (127-158). Cambridge University Press: New York, NY.

Le Roux, C. S., \& Mokhele, P. R. (2011), The persistence of violence in South Africa's schools: In search of solutions. Africa Education Review, 8:2, 318-335.

Loots, C. (2005), Violence in South Africa. From the Human Rights Institute of South Africa.

Marshall, C., \& Rossman, G. B. (2010), Designing qualitative research. London: Sage.

Mncube, V. and Harber, C. (2012). The Dynamics of Violence in South African schools: Draft Report.

Mncube, V. \& Netshitangani, T. (2014), Can Violence Reduce Violence in Schools? The Case of Corporal Punishment. Journal of Sociology and Social anthropology (JSSA), 5:1, 1-9.

Motsei, M (1998), "Experience of violence amongst young black men in Alexandra," Paper, ADAPT.

Ndebele, N. (2007), Perspectives on leadership challenges in South Africa. Perspectives in Education, 25:1, 1-8.

Neill, S. (2008), Disruptive pupil behaviour; its causes and effects, a survey analysed for the National

Union of Teachers, Interim Report, Institute of Education, University of Warwick.

Novak, J. M. (2002). Inviting educational leadership: Fulfilling potential and applying an ethical perspective to the educational process. New York, NY: Pearson Education.

OSHAKO, T. (1997), 'Tackling school violence worldwide: A comparative perspective of basic issues and challenges', in Oshako, T. (ed) Violence at school: Global issues and interventions, Paris: UNESCO/IBE.

Patton, M. Q. (2008), Utilization-focused evaluation. Newbury Park, CA: Sage.

Pinheiro, P. (2006), World Report on Violence Against Children, Geneva: United Nations.

PLAN. (2008), The Global Campaign To End Violence in Schools, Woking: PLAN.

Purkey, W. W. \& Novak, J. (1996,. Inviting school success: A self-concept approach to teaching, learning, and democratic practice. (3rd ed). New York: Wadsworth.

Purkey, W. W. \& Schmidt, J. J. (1996), Invitational counseling: A self-concept approach to professional practice. Pacific Grove, CA: Brooks/Cole.

Purkey, W. W. (2000), What students say to themselves: Internal dialogue and school success. Thousand Oaks, CA: Corwin Press.

Purkey, W. W, \& Siegel, B. L. (2003), Becoming an invitational leader: A new approach to professional and personal success. Atlanta, GA: Humanics Trade Group.

SACE School-based violence report: an overview of School-based Violence in South Africa: 2011

Scott Granberg-rademacker, J. (2007), Do school violence policies matter? An empirical analysis of four approaches to reduce school violence. Southwest Journal of Criminal Justice, 4:1, 3-29.

Shier, H. (2008), The causes of school violence. Minnesota: ABDO Publishing Company.

Shoffner, M. F. \& Vacc, N. A. (1999), Psychometric analysis of the Inviting School Safety Survey. Measurement and Evaluation in Counseling and Development, 32, 66-74.

Silverman, D. (ed.). (2010). Qualitative research. New Bury Park: Sage.

Smith, A. \& Vaux, T. (2003), Education, Conflict and International Development, London: DfID.

Smith, D., \& Smith, B. (2006, Feb/Mar). Perceptions of violence: The views of teachers who left urban schools. The High School Journal, 34-42.

South African Government Education Laws Amendment Act, 31 of 2007.

Stanley, P. H. \& Purkey, W. W. (1994), Student self-concept-as-learner: Does Invitational Education make a difference? Research in the Schools, 1:2, 15-22.

Strydom, H., \& Venter, L. (2002), Sampling and sampling methods. Research at grass roots for the social sciences and human service professions. Pretoria: Van Schaik.

The South African Human Rights Commission report on violence in schools (2008). United Nations Children's Fund (UNICEF). (2001), Children in war. <http://www.unicef.org/children-in-war/>. Accessed on 07 February 2014.

White, S. (2007), Boys, masculinity and school violence: Reaping what we sow. Gender and Education, 19:6, 729-737.

Zulu, B. M. \& Urbani, G. A. van der Merwe \& JL van der Walt. (2004), Violence as an impediment to a culture of teaching and learning in some South African schools. South African Journal of Education, 24:2, 170-5. 